\title{
Extending the Queen Bee Effect: How Hindustani Workers Cope with Disadvantage by Distancing the Self from the Group
}

\author{
Belle Derks* \\ Utrecht University

\section{Colette van Laar} \\ University of Leuven \\ Naomi Ellemers \\ Utrecht University

\section{Gauwrie Raghoe} \\ Leiden University
}

Previous research revealed that one way by which members of minority groups resist disadvantage is through strategic "self-group distancing" by evaluating this group negatively, describing themselves according to outgroup stereotypes and supporting the status hierarchy, hereby limiting societal change. Drawing upon recent work on the Queen Bee phenomenon among women at work, we explain selfgroup distancing as a coping response of low identified minority employees who experience social identity threat. Whereas queen bee behavior is often discussed as a response typical for women, new experimental data are presented revealing similar responses among ethnic minority employees. In parallel to queen bees, low identified Hindustanis reported less positive ingroup affect and presented themselves as more stereotypically Dutch when reminded of ethnic bias-but not in a control condition. This suggests that the Queen Bee phenomenon exemplifies a more generic individual mobility response to group disadvantage experienced by minority groups at work.

\footnotetext{
* Correspondence concerning this article should be addressed to Belle Derks, Utrecht University, Social and Organizational Psychology Unit, P.O. Box 80.140, 3508 TC Utrecht, The Netherlands, Tel: +31 (0)30-2534571, [e-mail: B.Derks@uu.nl].
} 
This special issue is concerned with how perceptions of group-based discrimination affect people's need to address their group's disadvantage, and the individual and collective ways in which members of disadvantaged groups do so (de Lemus \& Stroebe, 2015). Ample research has focused on the reasons why members of low status groups are often dissuaded from working toward collective status improvement, inducing them to pursue individual mobility instead (Ellemers \& Van Laar, 2010). Although some forms of individual mobility may be instrumental in improving the outcomes of the entire group (e.g., when group members access valuable resources and use their power to improve opportunities for other group members; Hansen, 2015), the focus of this contribution is on one specific form of individual mobility that actually damages opportunities for collective change: self-group distancing.

When members of low status groups distance the self from the group, their pursuit for individual success comes at the expense of the group's outcomes. This is because they validate the high status group's negative evaluation of other members of their (low status) group by actively distancing themselves from what is perceived as the group's stereotype. One arena in which we have observed this behavior is in our research program on the Queen Bee phenomenon among upwardly mobile professional women (Derks, Ellemers, Van Laar, \& de Groot, 2011; Derks, Van Laar, Ellemers, \& de Groot, 2011; Ellemers, Van Den Heuvel, De Gilder, Maass, \& Bonvini, 2004). In this work, we show that masculine organizational contexts induced some women to improve their individual opportunities by strategically presenting themselves as more masculine, evaluating the abilities of other women more negatively, and legitimizing gender inequality by denying that gender discrimination still exists. This form of self-group distancing, although possibly effective for individual women, is likely to damage the image of women more generally, and limits opportunities to achieve gender equality in the workplace.

Low status group members who actively distance themselves from their group are often judged negatively by other ingroup members (Van Laar, Bleeker, Ellemers, \& Meijer, 2014) and given derogatory labels like queen bee or oreo (African Americans who "act white"; Fordham \& Ogbu, 1986). Some previous research has sought to identify the motives for this ingroup damaging behavior by examining who these group members are, focusing on stable individual difference variables such as low self-esteem, traditional gender views, and system justifying beliefs that predict low status group members' support for the status quo (Cowan, Neighbors, DeLaMoreaux, \& Behnke, 1998; Jost \& Hunyadi, 2005). In this research, we take a more contextual approach based on social identity theory (Tajfel \& Turner, 1979) and show that self-group distancing is not a generic response of women and other minorities who buy into an illegitimate system and unscrupulously aim to improve their own career opportunities at the expense of their group. Instead, we argue that self-group distancing is a contextually induced and flexible way of 
coping with the social identity threat implied in performance settings that confront disadvantaged group members with their reduced opportunities.

In what follows, we first review evidence of self-group distancing responses, followed by an overview of our research into the Queen Bee phenomenon among women in the workplace that provides initial evidence for our theoretical analysis. Next, we establish generalizability of our reasoning to other low status groups by presenting new data that confirm the role of social identity threat in self-group distancing responses in Surinamese Hindustani workers in the Netherlands.

\section{Self-Group Distancing among Stigmatized Groups in Performance Settings}

It is a popular assumption that discrimination against minority groups comes from members of the majority and that simply placing more members of disadvantaged groups in positions of power will serve as a catalyst for improving diversity in higher management. Through mentoring, role modeling, and promoting junior ingroup members, minorities in high positions are expected to improve outcomes of their fellow ingroup members within their organization (for discussions, see Duguid, 2011; Mavin, 2008). However, a growing body of research shows that individually successful members of devalued groups are sometimes not willing to work for opportunities of their fellow ingroup members. In part, this is due to the fact that members of low status groups often do not see how group disadvantage also affects them personally, to realize that the lower outcomes of their group are illegitimate or that they could do something to change this (Becker, Zawadzki, \& Shields, 2014; Ellemers \& Barreto, 2009). Moreover, low status group members who are individually successful when this is not typical for their group may over time disidentify from their group, as they are increasingly seen, by themselves and others, as exceptional individuals who are nonprototypical for their group (Ellemers \& Barreto, 2009). Our current interest is not in such lack of collective action intentions among successful tokens and disidentification over time. Instead, we focus on why some of these successful individuals go one step further and flexibly manage how others see them by presenting themselves as distanced from their group in situations where this group is evaluated negatively.

Self-group distancing responses have been found among different groups and in different forms. One way in which group members can strategically distance themselves from their stigmatized group is by underlining their dissimilarities and social distance from other group members. For example, women in senior positions have been found to rate their own ambition and career commitment as higher than that of other women (Derks, Ellemers, et al., 2011). In the same vein, research on stereotype threat has found that African-American students distance themselves from their group psychologically and physically when primed with negative stereotypes about African Americans' intellectual ability through lower self-stereotyping (reporting lower interest for stereotypical activities such 
as basketball and hip-hop; see Steele \& Aronson, 1995), and by sitting further away from a low-performing African-American student (Cohen \& Garcia, 2005). Parallel responses are seen among gay men who distance themselves from the stereotype of gays as very feminine by expressing very negative opinions about other gays who act effeminately (Eguchi, 2009).

A second form of self-group distancing is when members of stigmatized groups actively try to assimilate into higher status groups by presenting themselves according to the stereotypes of this other group. For instance, a recent study among members of boards of directors in the Netherlands found that female board members described themselves in more masculine terms (i.e., more focused on achieving status) relative to other women with a comparable educational level and even male members of these boards (Lückerath-Rovers, de Bos, \& de Vries, 2013). Similarly, we found increased agentic self-descriptions among senior police women (Derks, Van Laar, et al., 2011). Similarly, "straight acting" gay men emphasize extreme masculinity in order to distance themselves from the stereotype of gays being effeminate (Eguchi, 2009).

Finally, and arguably most detrimental, group members can distance themselves from their group by actively legitimizing the current status hierarchy. They do so by agreeing with the negative stereotypes that exist about their group (while emphasizing that they are different so the stereotype should not be applied to them), by denying that the lower outcomes of their group are illegitimate, and by opposing actions aiming to redress current inequalities. For example, several studies have found that compared to men, women in executive positions are less likely to support and promote other women (Duguid, 2011; Garcia-Retamero \& Lopez-Zafra, 2006), and are more likely to endorse gender-biased perceptions of other women's career commitment (Derks, Ellemers, et al., 2011; Ellemers et al., 2004). Other work has shown that women who have reached executive positions in gender-biased contexts may deny that sexism still exists (Derks, Van Laar, et al., 2011), and become less supportive of gender equality programs as they advance in the organization ( $\mathrm{Ng} \&$ Chiu, 2001). Rather than "rocking the boat" and incurring personal costs, these successful tokens may thus support the status hierarchy in which they have realized their individual achievements.

Self-group distancing responses can seriously undermine the opportunities of other individuals belonging to the disadvantaged group, for several reasons. First, the success of individual group members is unlikely to change the negative stereotype of minority groups when upwardly mobile group members emphasize that their accomplishments are unique and not typical for the rest of the group (Ellemers \& Barreto, 2009). Second, although other group members may benefit from having successful ingroup role models, when these role models actively distance themselves from their group, they are more likely to demotivate rather than inspire other group members (Asgari, Dasgupta, \& Stout, 2012). Finally, self-group distancing responses can serve to legitimize the current status hierarchy. Negative 
stereotypes expressed and endorsed by representatives of the disadvantaged group (e.g., a senior woman conveying negative gender-stereotypical expectancies about a female subordinate) are more influential than similar opinions expressed by high status group members, as the former seem more credible and are less likely to be perceived as discriminatory (Baron, Burgess, \& Kao, 1991). Moreover, their denial that discrimination still exists and the opposition to affirmative action type measures programs that is part of self-group distancing can be used to blame the victims, rather than the system, for the lower outcomes of disadvantaged groups (Swim, Aikin, Hall, \& Hunter, 1995). As such, self-group distancing responses are part of the societal forces that keep low status groups in their place.

\section{Explaining Self-Group Distancing Responses: A Social Identity Analysis}

In our own work on self-group distancing responses among senior women, we have examined the role of organizational gender discrimination in the development of queen bee (QB) responses. In the popular media, QB behavior is often discussed as an abhorrent response typical of women and as evidence that not men but women are responsible for holding women back (Mavin, 2008; Sheppard \& Aquino, 2013). Taking a social identity perspective (Tajfel \& Turner, 1979) we, however, consider QB behavior as an individual mobility response that allows women to reach their potential in a setting in which their female social identity is devalued (Ellemers \& Van Laar, 2010). As described in detail in other contributions to this special issue, when people realize that parts of their social identity are viewed negatively (e.g., their gender, ethnicity, social class), this triggers a threat response (Górska \& Bilewicz, 2015; Jiménez-Moya, Spears, Rodríguez-Bailón, \& de Lemus, 2015). Women working in settings where their gender is devalued-be it through explicit derogatory comments, or more subtly through the largely male composition of the organization's management-will soon perceive their gender as limiting their advancement opportunities. We predict that this threat response induces some women to pursue individual mobility by flexibly distancing themselves from the stigmatized identity. Importantly, this also means that the self-group distancing response should be absent when there is no such threat and hence no need to protect social identity, as is the case in performance settings in which individuals' group membership is not a disadvantage.

Using a social identity perspective, we predict that not all group members are equally likely to show self-group distancing responses in the face of social identity threat. Whether group members collectively or individually cope with their devalued status is largely dependent on how important this group is to their identity (Ellemers, Spears, \& Doosje, 2002). People who identify strongly with their group and for whom this identity defines a large part of who they are, are likely to be concerned about the standing of their group. They will therefore be more motivated to collectively cope to improve their group's standing in the social 
hierarchy (e.g., by protesting gender inequality, mentoring women to reach their potential, etc.). However, group members who do not feel strongly connected to their group are more likely to be concerned with how being categorized as a woman will affect their individual outcomes (categorization threat; Branscombe, Ellemers, Spears, \& Doosje, 1999). To cope with this unsolicited categorization and emphasize their individuality, they flexibly distance themselves from the group when this could benefit them. Based on this reasoning, we argue that QB type of self-distancing responses should most likely be found: (1) in work settings in which low status group members are devalued (high social identity threat), (2) among group members who do not consider their group as an important part of their identity at work (low group identification).

In our prior work, we indeed found evidence for such interactive effects of gender devaluation and gender identification on QB responses, in support of our social identity analysis. For example, among senior women in the police force (Derks, Van Laar, et al., 2011), we manipulated the salience of gender bias by asking women about gender discrimination at work (vs. a control condition). Results showed that QB responses (i.e., masculine self-presentation, emphasizing differences with other women and denial of discrimination) were most clearly observed among women who were asked about gender discrimination at work, but only when they reported relatively low levels of gender identification. Importantly, this difference in responses between low and highly identified women was not significant in the absence of gender bias primes. This study also showed that senior police women with high gender identification responded to gender discrimination primes with collective coping: They reported a higher willingness to mentor other women and were more in favor of affirmative action type measures.

\section{The Current Study}

Results such as these suggest that QB responses in women in executive positions indeed indicate how low gender-identified female professionals cope with the social identity threat that results from an organizational setting that devalues women. Nevertheless, it is as yet unclear whether this response is specific to women, or also generalizes to other devalued groups. To be able to assess whether this phenomenon indeed represents a more general self-group distancing coping strategy, it is imperative to show parallel self-group distancing responses among similarly disadvantaged groups at work. Therefore, in this study, we performed a conceptual replication of the experimental field study among senior police women described above, in a different negatively stereotyped group. We focused on Surinamese Hindustanis in work settings in the Netherlands, and tested whether they showed self-group distancing responses ("acting Dutch") parallel to the QB phenomenon in response to ethnic discrimination, to the degree that they experienced low ethnic identification. 
Although behaviors that we see as indicative of self-group distancing among ethnic minority groups have been reported in the literature, no research to date has actually examined this as a coping response elicited when low identified group members are confronted with discrimination based on their group membership. We assessed their negative attitudes about other Hindustanis, the tendency to present themselves in line with the stereotype of Dutch workers, and their willingness to support the legitimacy of the current system by denying the existence of discrimination. We predicted more "acting Dutch" responses among low (rather than high) ethnically identified respondents when asked about group-based discrimination. In the control condition, we did not expect differences between low and high identifiers. By contrast, we anticipated high (but not low) identifiers to respond to identity threat through collective coping strategies, in this case by measuring "social creativity." Previous work has revealed that highly identified group members do not necessarily promote their group by comparing it with the outgroup on status-defining dimensions like salary or competence, but by "creatively" emphasizing the group's positive distinctiveness on other positive dimensions (e.g., women emphasizing that they are more trustworthy than men; Derks, Van Laar, \& Ellemers, 2007; Leach \& Livingstone, 2015).

Surinamese Hindustanis are one of the larger ethnic minority groups in the Netherlands (approximately 1\% of the total population). Research shows that while employers' perceptions of Surinamese employees have become more positive (especially compared to Moroccan and Turkish immigrants), Surinamese Dutch still suffer from disadvantage in the labor market, with higher unemployment rates, lower likelihood of obtaining permanent positions, and high rates of reported ethnic discrimination (Nievers \& Andriessen, 2010). In this study, we examined whether reminding Hindustanis of this ethnic discrimination would trigger selfgroup distancing responses among those who are weakly identified.

\section{Method}

\section{Participants}

Participants were 78 Surinamese Hindustani employees $\left(M_{\text {age }}=37.74\right.$, $S D=12.63 ; 53 \%$ men), with they themselves $(56 \%)$ or at least one of their parents $(97 \%)$ born in Surinam. The experimental online field study was programmed with Qualtrics software. As a reward, one randomly selected participant was awarded a coupon of $€ 100$.

\section{Measures}

All variables were measured on 7 -point scales $(1=$ completely disagree, $7=$ completely agree). 
Ethnic identification. Given that group identification can vary from one setting to the next (e.g., at work vs. at home; Turner, Oakes, Haslam, \& McGarty, 1994), in order to predict work-related behavior, we measured ethnic identification in this specific context. We used the solidarity and individual self-stereotyping subscales from the multicomponent identification measure developed by Leach and colleagues (2008; five items, $\alpha=.94$; e.g., "At work I feel a bond with other Hindustanis," "At work I feel similar to other Hindustanis").

\section{Self-Group Distancing Responses}

Positive and negative affect toward Hindustani coworkers. This was measured with four positive ("When I think of Hindustanis, I feel interest/appreciation/approval/joy"; $\alpha=.89$ ) and five negative items ("When I think of Hindustanis, I feel low appreciation/disapproval/aversion/reluctance/sadness"; $\alpha=.88)$.

Denial of discrimination. This was measured with two items ("It's my impression that discrimination at work toward Hindustani employees no longer occurs," "I think that many Hindustani employees still experience prejudice" [reverse coded]; Spearman-Brown $\rho=.51$ ).

Self-descriptions with Dutch versus Hindustani characteristics. To establish which characteristics Surinamese Hindustanis perceived as stereotypically Hindustani and Dutch, we performed two pilot tests.

Pilot 1. Thirty-one Surinamese Hindustanis (19 females, $M_{\text {age }}=28.29$ years, $S D=13.36$ ) were asked in an open-ended questionnaire to freely list positive and negative characteristics that they saw as typical for Hindustani and Dutch people. For Hindustanis, positive characteristics mentioned most often were hospitable, sociable, family-minded, conscientious, modest, helpful, polite, and caring. Negative characteristics frequently mentioned were gossipy, stingy, jealous, meddlesome, risk-averse, unassertive, and narrow-minded. For the Dutch target group, positive characteristics mentioned most often were punctual, down-to-earth, professional, independent, and direct. Negative characteristics were greedy, dominant, intolerant toward foreigners, and arrogant.

Using characteristics from Pilot 1 that were work-related, we created 10 test items, 5 indicating stereotypically Dutch characteristics (punctuality, being downto-earth, directness, independence, and professionalism), and 5 comprising stereotypically Hindustani characteristics (modesty, unassertiveness [two items], closedmindedness, and risk-avoidant).

Pilot 2. To determine whether the test items were indeed seen as more typical for one group over the other, 31 Surinamese Hindustanis (18 females, $M_{\text {age }}=$ 31.26 years, $S D=10.07$ ) were asked to indicate to what degree each item fit 
Table 1. Group Ratings for Stereotypically Dutch and Hindustani Characteristics in Pilot 2

\begin{tabular}{lccccc}
\hline Characteristic & Hindustani $M(S D)$ & Dutch $M(S D)$ & $t$ & $\mathrm{df}^{\mathrm{b}}$ & $p$ \\
\hline Hindustani: & & & & & \\
$\quad$ Modest & $4.61(1.28)$ & $3.10(1.49)$ & 4.50 & 30 & .000 \\
Risk-avoidant & $5.03(1.47)$ & $4.23(1.14)$ & 2.63 & 29 & .014 \\
$\quad$ Unassertive $1^{\mathrm{a}}$ & $2.90(1.65)$ & $1.40(1.10)$ & 4.53 & 29 & .000 \\
Unassertive 2 $^{\mathrm{a}}$ & $3.14(1.30)$ & $2.14(1.30)$ & 3.51 & 28 & .002 \\
$\quad$ Closed-minded $^{\mathrm{a}}$ & $2.41(1.21)$ & $2.34(1.21)$ & 0.23 & 28 & .82 \\
Dutch: $_{\text {Independent }}$ & $3.00(1.51)$ & $3.77(1.54)$ & -2.83 & 30 & .008 \\
$\quad$ Punctual & $5.03(1.21)$ & $4.79(1.11)$ & 1.19 & 28 & .24 \\
Professional & $4.45(1.38)$ & $4.28(1.16)$ & 0.52 & 28 & .61 \\
Direct & $3.18(1.25)$ & $5.25(1.14)$ & -6.46 & 27 & .000 \\
$\quad$ Down-to-earth & $4.00(1.41)$ & $4.88(1.15)$ & -2.67 & $15^{\mathrm{c}}$ & .017 \\
\hline
\end{tabular}

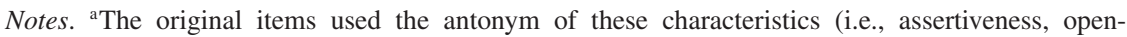
mindedness) and were reverse coded before analysis.

${ }^{b}$ Degrees of freedom vary due to missing values.

${ }^{\mathrm{c}}$ Due to a programming error, $n=15$ for this item.

their image of the average Hindustani and Dutch employee (e.g., "The average Hindustani employee has a modest attitude at work"; 1 = completely disagree, 7 = completely agree). Results are depicted in Table 1. Based on these results, three characteristics that did not significantly differentiate between the two groups were dropped (i.e., closed-minded, punctual, and professional).

With the remaining items, two scales were created for the main study. The first measured Dutch self-presentation (independent ["At work I am not so much influenced by the opinions of others"], direct ["At work I have a direct way of expressing my opinion to colleagues"], down-to-earth ["At work I have a down-to-earth attitude and don't easily get emotional or flustered"], $\alpha=.56$ ). The second assessed Hindustani self-presentation (modest ["At work I have a modest attitude"], unassertiveness ["At work I stick up for myself" and "At work I am assertive and self-assured," both reverse coded], $\alpha=.59$; risk-avoidant was dropped as it reduced the reliability of the scale).

Social creativity. In order to tap into group-based coping strategies typically used by high identifiers, we examined whether they showed amplified ingroup favoritism on a dimension that positively characterized the ingroup. As the pilot study revealed that Hindustani's saw conscientiousness as a positive ingroup characteristic, we examined whether group members might use this dimension to protect their social identity. We measured perceived work conscientiousness of Dutch and Hindustani employees with three items per target group (e.g., "At work 
the boss can count on the average Dutch/Hindustani employee"; $\alpha_{\text {Dutch }}=.88$; $\alpha_{\text {Hindustani }}=.88$ ). Social creativity was assessed by deducting the mean score for Dutch employees from the mean score for Hindustani employees (positive scores indicate social creativity).

Background variables. We assessed demographics and relevant background variables (age, gender, country of birth of participant him/herself, and his/her parents, percentage of Hindustani employees in work setting).

\section{Procedure}

Identical to our work on QB behavior among police women (Derks, Van Laar, et al., 2011), we first measured ethnic identification and then primed ethnic bias versus control. We did this by inducing a temporary focus on either the presence or absence of ethnic discrimination. Participants read how work environments could differ in the degree to which people are evaluated based on personal characteristics or on ethnicity and associated stereotypes. Subsequently, participants in the ethnic bias condition were asked to describe an experience in which they had experienced discrimination due to their Hindustani ethnicity rather than being judged on their personal merit. Participants in the control condition were asked to write about an experience in which their personal qualifications had been acknowledged and ethnic bias had not been an issue. To induce participants to relive this experience, they were also asked to report their emotions, and to specify how this experience had affected their career.

Following the manipulation, dependent measures and background measures were assessed, after which participants were debriefed.

\section{Results}

\section{Correlations}

Analysis of correlations between background variables (age, gender, percentage of Hindustani employees), independent (identification and condition) and dependent variables (self-group distancing responses and social creativity; see Table 2) showed that participants' identification with other Hindustanis at work was positively related to the percentage of Hindustani employees present at work. Additionally, the background variables correlated significantly with some of the dependent variables. Older participants reported less negative affect toward their ingroup, and Hindustani women on the one hand presented themselves more stereotypically (as less Dutch and more Hindustani) than men, but on the other hand reported more negative ingroup affect than men did. Finally, participants in work environments with more Hindustanis not only were more likely to identify 


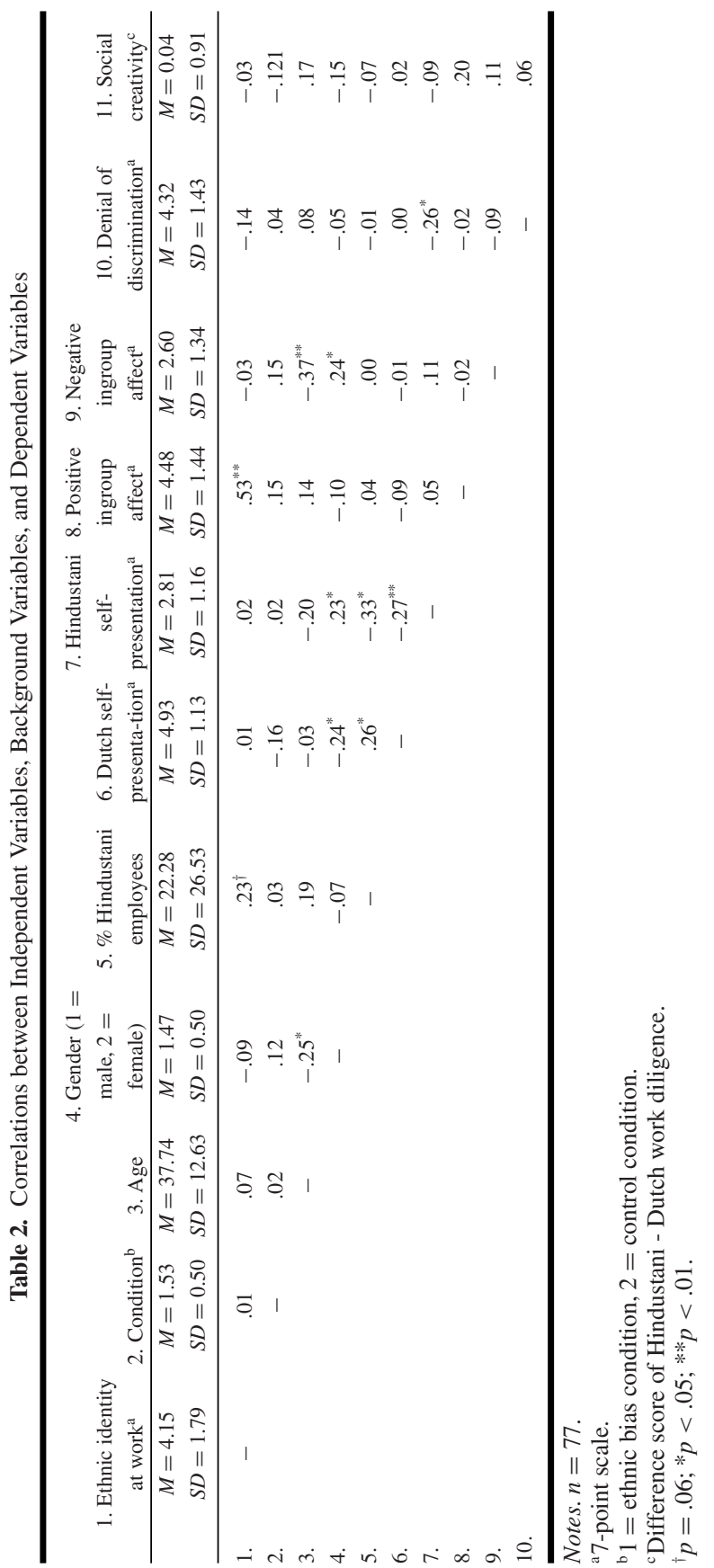


with their ethnicity, but also presented themselves as more Dutch, and less Hindustani. To control for these correlations when testing the hypothesized effects, we included age, gender, and percentage of Hindustanis at work as covariates in all analyses.

\section{Overview of Regression Analyses}

We performed hierarchical regression analyses in which the (standardized) background variables age, gender, and percentage of Hindustanis at work were entered in step 1 , the main effects of condition $(1=$ ethnic bias prime; $2=$ control) and ethnic identification (standardized) in step 2, and the interaction between condition and ethnic identification in step 3. Significant interaction effects were examined by testing the simple slopes of condition for participants with relatively low $(M-1 S D)$ and high ethnic identification $(M+1 S D)$, and by calculating simple slopes of ethnic identification per experimental condition (Aiken \& West, 1991). Due to missing values, degrees of freedom differ between analyses.

\section{Positive and Negative Affect toward Hindustani Coworkers}

Overall, low identifiers reported less positive affect toward their ingroup than high identifiers, $b=0.79, S E=0.15, t(59)=5.14, p<.001$, semipartial $r^{2}=.29$. As predicted, this effect was moderated by condition, $b=-0.75, S E$ $=0.30, t(58)=-2.49, p=.016$, semipartial $r^{2}=.06$ (Figure 1). Simple slope analyses revealed three significant slopes. First, whereas high identifiers were not affected by condition $(p=.21)$, low identifiers reported less positive affect toward their ingroup after being primed with ethnic bias than in the control condition, $b=0.95, S E=0.39, t(58)=2.46, p=.017$, semipartial $r^{2}=.06$. Examining the interaction in a different way, although in both conditions high identifiers reported more positive affect toward their ingroup than low identifiers, this effect was stronger in the ethnic bias condition, $b=1.22, S E=.23, t(58)=5.37$, $p<.001$, semipartial $r^{2}=.29$, than in the control condition, $b=0.47, S E=.20$, $t(58)=2.39, p=.02$, semipartial $r^{2}=.06$. No significant main or interaction effects were found on negative affect toward the ingroup ( $t$ 's $<1.44 ; p$ 's $>.16$ ).

\section{Dutch and Hindustani Self-Presentation}

In line with predictions, analysis of self-presentation in stereotypically Dutch work characteristics revealed a significant interaction effect between condition and identification, $b=0.80, S E=.27, t(58)=2.97, p=.004$, semipartial $r^{2}=.11$ (Figure 1). As predicted, low identifiers presented themselves more in stereotypically Dutch terms in the ethnic bias condition than in the control 

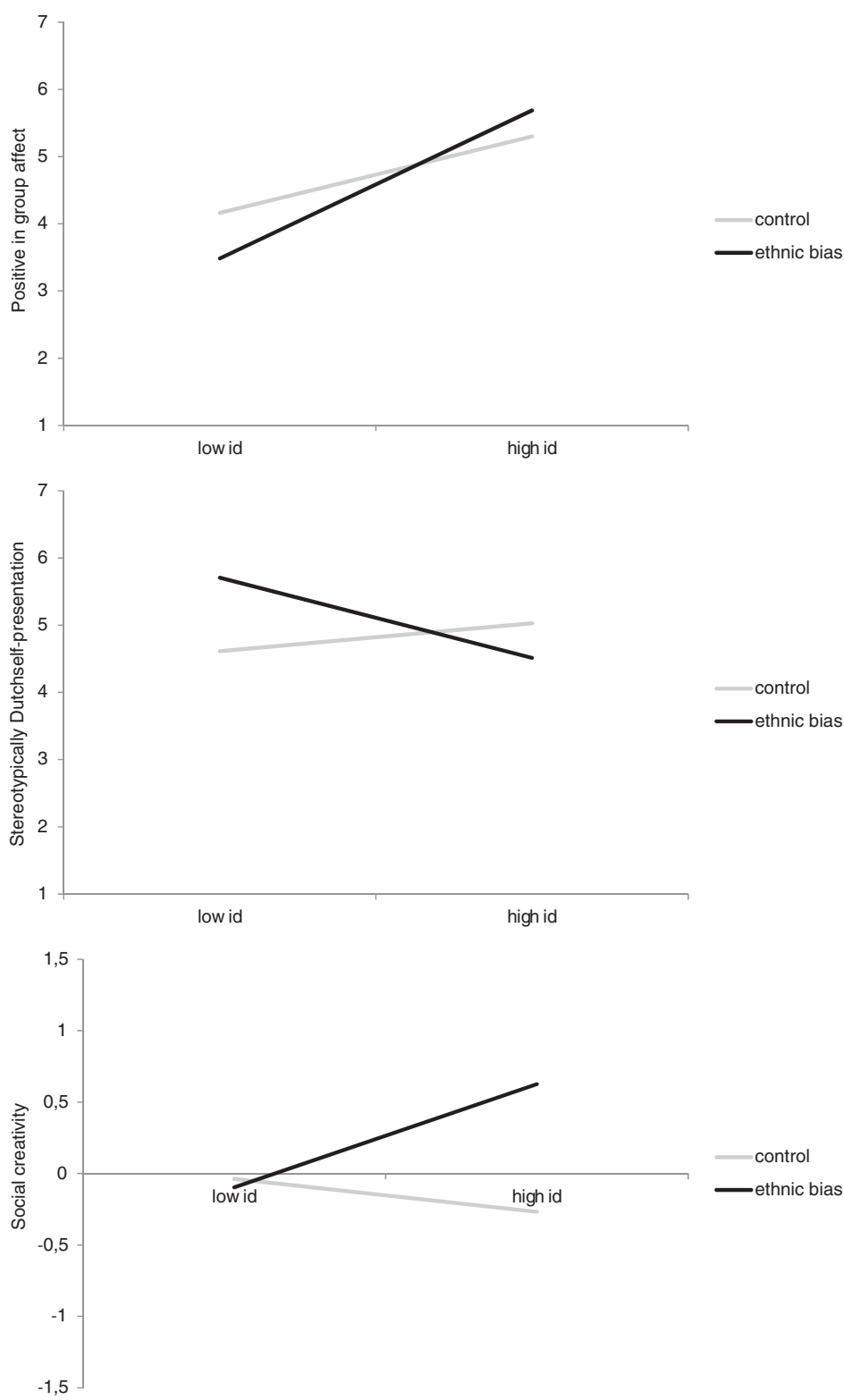

Fig. 1. Positive affect reported toward the ingroup (upper panel), self-presentation in stereotypically Dutch work characteristics (middle panel), and social creativity (lower panel: ingroup bias in reported conscientiousness; Hindustani employees-Dutch employees) for participants with relatively low (-1 $S D)$ and high $(+1 S D)$ levels of ethnic identification in the ethnic bias condition and control condition. 
condition, $b=-1.09, S E=.35, t(58)=-3.16, p=.003$, semipartial $r^{2}=$ .12. For high identifiers, there was no effect of condition $(p=.19)$. Testing the slopes per condition we found that, when they were primed with ethnic bias, low identifiers presented themselves as more stereotypically Dutch than high identifiers, $b=-0.60, S E=.20, t(58)=-2.93, p=.005$, semipartial $r^{2}=.11$, but in the control condition, there was no effect of identification $(p=.24)$. On Hindustani characteristics, we found no significant effects $(t$ 's $<1.35$; $p$ 's $>.18)$.

\section{Denial of Discrimination}

In contrast to QBs in our work with women, regression analysis revealed no significant effects of identification, condition, or its interaction on denial of discrimination (all $p$ 's $>.29$ ). The mean score (4.32) revealed that this was not due to a floor or ceiling effect.

\section{Social Creativity}

We found a significant interaction effect on social creativity (ingroup bias on the ingroup dimension 'conscientiousness'), $b=-0.48, S E=0.24, t(58)=-1.96$, $p=.055$, semipartial $r^{2}=.06$ (Figure 1 ). As expected, high identifiers showed stronger social creativity after being primed with ethnic bias than in the control condition, $b=-0.89, S E=.35, t(58)=2.56, p=.013$, semipartial $r^{2}=.09$. For low identifiers, there was no effect of condition $(p=.85)$. Moreover, testing the slopes of low and high identifiers per condition revealed that, when primed with ethnic bias, high identifiers showed stronger social creativity than low identifiers, $b=0.36, S E=0.18, t(58)=1.97, p=.05$, semipartial $r^{2}=.06$. In the control condition, there was no effect of identification $(p=.46)$.

\section{Discussion}

When successful members of disadvantaged groups distance themselves from their group in order to achieve higher personal outcomes, this can hamper opportunities for social change. Rather than focusing on stable individual difference explanations of ingroup-undermining and status-legitimizing responses among members of disadvantaged groups, we show that work contexts can stimulate versus reduce a flexible self-group distancing response among members of disadvantaged groups. Building on a social identity perspective, we show that reminders of inequality at work induce those who are not strongly identified with their group to distance themselves from their group. Distancing does not occur, however, when people are reminded of instances in which their individual characteristics were acknowledged, indicating that self-group distancing is a flexible rather than stable 
response. Importantly, by showing these responses among Hindustani employees in the Netherlands, the current data generalize this explanatory process beyond women in the workplace, contesting popular accounts of the QB phenomenon as due to differences in ingroup loyalty among men and women employees.

The present data confirm that some Hindustani employees distance themselves from their devalued ethnic group by reporting lower positive affect about their Hindustani coworkers and presenting themselves as having more stereotypically Dutch characteristics (e.g., down-to-earth, direct). Vitally, they do so under the same conditions as QB responses were found among women: low group identification combined with discrimination primes. Despite these similarities in the response patterns observed among women and Hindustanis, there also was a notable difference. While low identified Hindustani workers presented themselves as stereotypically Dutch and reported less positive affect toward their ethnic ingroup in response to discrimination, they were not especially prone to deny the existence of ingroup discrimination, although this has been found as part of the response pattern displayed in QB research (Derks, Van Laar, et al., 2011).

Although the "acting Dutch" response found here was not completely identical to the QB response, the self-group distancing pattern we found occurred under the same conditions as the QB phenomenon. Moreover, we think that these differences between QB and "acting Dutch" responses likely reflect the different nature of a categorization in terms of ethnic origin compared to gender. It is possible that low identifying minority group members distance themselves from their group in ways that they think will be accepted. Whether ethnic minorities will flat out deny the existence of continuing ethnic discrimination in order to improve their individual opportunities (as we assessed here) may depend on the social climate and public opinion regarding social equality and the existence of ethnic discrimination. It could be argued that the prevalence of ethnic discrimination is more visible and discussed in the media than the existence of continuing gender discrimination. In a climate in which discussions about gender equality tend to emphasize that opportunities are based on individual merit, women can distance themselves from their group by claiming that the current system is legitimate, whereas this would be less accepted in a more feminist climate. Although we did not find increased denial of the existence of ethnic discrimination among low ethnically identified Hindustani, maybe we would have found increased system legitimizing responses on items assessing more widely accepted system justifying opinions.

In addition to self-group distancing responses, we also found that when faced with group-based discrimination, some group members are motivated to work to improve the image of their group: Rather than distancing themselves from the group, highly identified Hindustanis showed social creativity by emphasizing their group's positive distinctiveness from Dutch employees on a competence dimension on which Hindustanis are positively stereotyped (i.e., conscientiousness). By focusing on the positive ingroup stereotype, this socially creative coping 
strategy serves to improve the image of the group as a whole, instead of trying to individually escape the negative group stereotype (Derks et al., 2007; Leach \& Livingstone, 2015).

This study established that QB-type self-group distancing responses do not occur among women only, and that these are more generic responses to social inequality. At first sight, it might seem that those who identify weakly with the group should be less likely to react to group-based discrimination, as their sense of self is not clearly tied to a negative image others may have of the group. However, it is important to make a distinction between different types of threat. We argue that, unlike high identifiers, low identifiers are not suffering from the fact that the value of their group is threatened (group value threat; Branscombe et al., 1999) but that low identifiers experience threat due to their categorization as a member of a group they do not consider self-relevant in the work context. Here, the threat stems from lack of alignment between preferred self-views and treatment by others (Barreto \& Ellemers, 2003), as well as the fear that the performance of other group members will confirm stereotypical expectations, and will reflect negatively on the self (Cohen \& Garcia, 2005; Duguid, 2011). Hence, attempts to address this type of threat with self-group distancing emphasize the individual's preferred self-view as being distinct from the group.

An interesting aspect of the results is that participants distanced themselves from the group by emphasizing the applicability of the outgroup stereotype to the self - not by denying the applicability of stereotypical ingroup traits. This finding converges with results from our previous studies in which gender bias induced low gender identified women to emphasize their masculine characteristics but not to deemphasize their femininity. Again, whether minorities will deemphasize ingroup stereotypes may be a function of what seems to be accepted by others. Possible women and ethnic minorities do not think it will be accepted if they deemphasize the applicability of stereotypical ingroup traits. However, previous work has found this behavior among gay men who distance themselves from effeminate traits that were seen as stereotypical for their ingroup (Eguchi, 2009). This also resonates with previous work on minority group members who try to find ways to retain a sense of commitment to their ethnic identity while seeking inclusion and acceptance in the host society (Van Laar et al., 2014). This prior research and this work also suggest that when minority group members continue to behave in ways that characterize their original identity, this does not necessarily imply that they are unwilling to adapt to normative requirements of the host society (Van Laar, Derks, \& Ellemers, 2013). Thus, even though the common sense view might be that people simply have to choose between competing identities (being masculine/Dutch or being feminine/Hindustani), there is by now converging evidence suggesting that the real challenge minority group members face is how to accommodate their sense of having a dual identity (Kulich, Lorenzi-Cioldi, 
Iacoviello, 2015). The current results add to this body of work, showing the negotiation of identity under threatening conditions.

While this research distinguishes between individuals who report low versus high ingroup identification in the work context, it is important to note that we do not conceive of high versus low group identification as another individual difference variable. Instead, in line with social categorization theory (Turner et al., 1994), we assume that feelings of identification and the willingness to be considered as a group member are likely to vary by context. Thus, women and ethnic minorities can show reduced identification with their group at work, for instance as a coping response that develops over time, while being more connected to their group in a private setting. For instance, the same individual who is very reluctant to be seen as someone with a Hindustani background when at work, might be perfectly happy to be seen as such outside of work (e.g., when dating, or with family).

This research is not without limitations. First, the manipulation of ethnic bias (vs. control) does not allow us to draw conclusions about the active ingredient of our manipulation. To allow conceptual replication of the conditions under which QB responses were triggered in our previous work (Derks, Van Laar, et al., 2011), we used the exact same manipulation. This manipulation combined two aspects, namely reminding people of previous outcomes that were either groupbased versus individually based (essentially manipulating categorization), as well as reminding them of negative versus positive work-related outcomes. While the resulting ethnic bias condition clearly is a social identity-threatening condition, whereas the control condition is designed to offset any threats to social identity, this leaves the question as to which aspect was more paramount in causing the effects.

Additionally, although the results for stereotypically Dutch self-presentation were as predicted, we must note that the newly created scales measuring Dutch versus Hindustani characteristics had relatively low reliability. This may in part be because, compared with the unidimensional construct of masculinity that was used in the QB studies, the characteristics that Hindustanis perceived as stereotypically Dutch (e.g., being direct, independent, and down-to-earth) were multidimensional. Moreover, although we based these scales on pilot investigations, it is very likely that Hindustanis differ in their perceptions of what is stereotypically Dutch behavior, leading participants to emphasize different parts of the Dutch stereotype. Additionally, because in creating the scales we did not control for trait valence, we cannot rule out the possibility that the Dutch characteristics that were used were more positive in valence than the Hindustani characteristics. Although we think that valence differences between stereotypes describing high and low status groups are part and parcel of the process leading to self-group distancing responses, in this study, we cannot determine to what degree participants were describing themselves as Dutch rather than simply describing themselves more positively. Therefore, in future research, we need to separate valence from stereotypicality 
by assessing participants' valence perceptions in a pilot study and creating scales with positive and negative traits that are typical of the high status group.

\section{Practical Implications}

The results of this research have significant policy implications. First, it is important to note that responses to discrimination experiences may differ, depending on the level of group identification. While high identifiers are likely inclined to welcome and support measures targeting their group as a whole, we anticipate low identifiers to be less inclined to favor such policies. At best, they will be reluctant to take advantage of such opportunities offered to them personally. At worst, these measures threaten their social identity at work, leading them to actively protest or work against the introduction of such measures, preventing others from benefiting from affirmative action. The introduction of equality policies thus requires great care, not only to prevent that majority group members object to this as a form of "reverse discrimination," but also to make sure that such policies actually are accepted as a valid form of support by the disadvantaged minority-especially by those who are reluctant to identify themselves as such.

As a first step toward developing procedures that take such sensitivities into account, it is important to consider why minority group members with low group identification may oppose such measures. As discussed above, low identifiers are likely to experience categorization threat when they are offered promotion opportunities that target them as members of a disadvantaged group needing additional support, rather than a high-potential employee. They become concerned that majority group members have negative stereotypical expectations of their personal performance, and that affirmative action policies may damage their group's image even further. In order to think of ways to overcome this, we can consider the "control" condition we induced in this research. Affirming people on an individual level, by explicitly reminding them of situations in which they were judged on individual merit reduced the tendency of low identified group members to distance the self from the group. Hence, they might be more accepting of and willing to benefit from measures supporting the ingroup when these measures are introduced as aimed toward improving individual opportunities for high-potential individuals rather than toward increasing the diversity in executive positions. At the same time of having these benefits for low identified group members, we must note that for high identifiers the emphasis on personal merit in the control condition might have adverse effects, as it undermined their tendency to promote the ingroup's image, as we also observed in previous work (Derks, Van Laar, \& Ellemers, 2009; Derks, Van Laar, et al., 2011). For them other interventions are needed to reduce identity threat in a way that does not reduce their collective action motivation (e.g., group affirmation strategies, see Derks et al., 2009). 


\section{Conclusion}

This study revealed that self-group distancing responses in the workplace can be found among ethnic minorities with relatively low ethnic identification in response to reminders of the ethnic discrimination they encounter at work. The similarity of the responses of Hindustani employees in this study with QB responses found in previous work, suggests that the QB phenomenon is not a response typical of women in leadership positions. Instead, QB behavior is an example of a more generic self-group distancing response evoked among members of groups that are disadvantaged in the workplace.

\section{References}

Aiken, L. S., \& West, S. G. (1991). Multiple regression: Testing and interpreting interactions. Newbury Park, CA: Sage.

Asgari, S., Dasgupta, N., \& Stout, J. G. (2012). When do counterstereotypic ingroup members inspire versus deflate? The effect of successful professional women on young women's leadership self-concept. Personality and Social Psychology Bulletin, 38, 370-383. doi: 10.1177/0146167211431968.

Baron, R. S., Burgess, M. L., \& Kao, C. F. (1991). Detecting and labeling prejudice: Do female perpetrators go undetected? Personality and Social Psychology Bulletin, 17, 115-123. doi: $10.1177 / 014616729101700201$.

Barreto, M., \& Ellemers, N. (2003). The effects of being categorised: The interplay between internal and external social identities. In W. Stroebe \& M. Hewstone (Eds.), European review of social psychology (Vol. 14, pp. 139-170). Hove, UK: Psychology Press/Taylor \& Francis.

Becker, J. C., Zawadzki, M. J., \& Shields, S. A. (2014). Confronting and reducing sexism: A call for research on intervention. Journal of Social Issues, 70, 603-614.

Branscombe, N. R., Ellemers, N., Spears, R., \& Doosje, B. (1999). The context and content of social identity threat. In B. Doosje, N. Ellemers \& R. Spears (Eds.), Social identity: Context, commitment, content (pp. 35-58). Oxford, UK: Blackwell Science.

Cohen, G. L., \& Garcia, J. (2005). "I am us": Negative stereotypes as collective threats. Journal of Personality and Social Psychology, 89, 566-582. doi: 10.1037/0022-3514.89.4.566.

Cowan, G., Neighbors, C., DeLaMoreaux, J., \& Behnke, C. (1998). Women's hostility toward women. Psychology of Women Quarterly, 22, 267-284. doi: 10.1111/j.1471-6402.1998.tb00154.x.

de Lemus, S., \& Stroebe, K. (2015). Resisting and confronting disadvantage: From individual coping to societal change. Journal of Social Issues, 71(3), 441-645.

Derks, B., Van Laar, C., \& Ellemers, N. (2007). Social creativity strikes back: Improving motivated performance of low status group members by valuing ingroup dimensions. European Journal of Social Psychology, 37, 490-493. doi: 10.1002/ejsp.375.

Derks, B., Van Laar, C., \& Ellemers, N. (2009). Working for the self or working for the group: How self- versus group affirmation affects collective behavior in low-status groups. Journal of Personality and Social Psychology, 96, 183-202. doi: 10.1037/n0013068.

Derks, B., Ellemers, N., Van Laar, C., \& de Groot, K. (2011). Do sexist organizational cultures create the queen bee? British Journal of Social Psychology, 50, 519-535. doi: $10.1348 / 014466610 \times 525280$.

Derks, B., Van Laar, C., Ellemers, N., \& de Groot, K. (2011). Gender-bias primes elicit queenbee responses among senior policewomen. Psychological Science, 22, 1243-1249. doi: $10.1177 / 0956797611417258$.

Duguid, M. (2011). Female tokens in high-prestige work groups: Catalysts or inhibitors of group diversification? Organizational Behavior and Human Decision Processes, 116, 104-115. doi: 10.1016/j.obhdp.2011.05.009. 
Eguchi, S. (2009). Negotiating hegemonic masculinity: The rhetorical strategy of "straight-acting" among gay men. Journal of Intercultural Communication Research, 38, 193-209. doi: 10.1080/17475759.2009.508892.

Ellemers, N., \& Barreto, M. (2009). Collective action in modern times: How modern expressions of prejudice prevent collective action. Journal of Social Issues, 65, 749-768. doi: 10.1111/j.15404560.2009.01621.x.

Ellemers, N., \& Van Laar, C. (2010). Individual mobility: The opportunities and challenges members of devalued groups encounter when trying to avoid group-based discrimination. In J. Dovidio, M. Hewstone, P. Glick \& V. Esses (Eds.), Handbook of prejudice and discrimination (pp. 561-576). London, UK: Sage.

Ellemers, N., Spears, R., \& Doosje, B. (2002). Self and social identity. Annual Review of Psychology, 53, 161-186. doi: 10.1146/annurev.psych.53.100901.135228.

Ellemers, N., Van Den Heuvel, H., De Gilder, D., Maass, A., \& Bonvini, A. (2004). The underrepresentation of women in science: Differential commitment or the queen bee syndrome? British Journal of Social Psychology, 43(3), 315-338. doi: 10.1348/0144666042037999.

Fordham, S., \& Ogbu, J. U. (1986). Black students' school success: Coping with the "burden of acting White." Urban Review, 18(3), 176-206. doi:10.1007/BF01112192.

Garcia-Retamero, R., \& Lopez-Zafra, E. (2006). Prejudice against women in male-congenial environments: Perceptions of gender role congruity in leadership. Sex Roles, 55(1-2), 51-61. doi:10.1007/s11199-006-9068-1.

Górska, P., \& Bilewicz, M. (2015). When “a group in itself” becomes “a group for itself”: Overcoming inhibitory effects of superordinate categorization on LGBTQ individuals. Journal of Social Issues, 71(3), 554-575.

Hansen, N. (2015). The development of psychological capacity for action: The empowering effect of a microfinance programme on women in Sri Lanka. Journal of Social Issues, 71(3), 597-613.

Jiménez-Moya, G., Spears, R., Rodríguez-Bailón, R., \& de Lemus, S. (2015). By any means necessary? When and why low group identification paradoxically predicts radical collective action. Journal of Social Issues, 71(3), 517-535.

Jost, J. T., \& Hunyadi, O. (2005). Antecedents and consequences of system justifying ideologies. Current Directions in Psychological Science, 14, 260-265. doi:10.1111/j.0963-7214.2005.00377.x.

Kulich, C., Lorenzi-Cioldi, F., \& Iacoviello, V. (2015). Moving across status lines: Low concern for the ingroup and group identification. Journal of Social Issues, 71(3), 453-475.

Leach, C. W., \& Livingstone, A. G. (2015). Contesting the meaning of intergroup disadvantage: Towards a psychology of resistance. Journal of Social Issues, 71(3), 614-632.

Leach, C. W., van Zomeren, M., Zebel, S., Vliek, M. L. W., Pennekamp, S. F., Doosje, B., \& Spears, R. (2008). Group-level self-definition and self-investment: A hierarchical (multicomponent) model of in-group identification. Journal of Personality and Social Psychology, 95(1), 144-165. doi: 10.1037/0022-3514.95.1.144.

Lückerath-Rovers, M., de Bos, A., \& de Vries, R. (2013). Nationaal Commissarissen Onderzoek 2013: Rollen en Drijfveren van de Commissaris [National investigation on members of boards of directors 2013]. Tilburg, the Netherlands: TiasNimbas.

Mavin, S. (2008). Queen bees, wannabees, and afraid to bees: No more 'best enemies' for women in management? British Journal of Management, 19, S75-S84. doi: 10.1111/j.14678551.2008.00573.x.

Ng, C. W., \& Chiu, W. C. K. (2001). Managing equal opportunities for women: Sorting the friends from the foes. Human Resource Management Journal, 11(1), 75-88. doi: 10.1111/j.17488583.2001.tb00033.x.

Nievers, E., \& Andriessen, I. (2010). Discriminatiemonitor niet-westerse migranten op de arbeidsmarkt 2010 [Discrimination monitor non-Western immigrant in the labour market 2010]. The Hague: Sociaal en Cultureel Planbureau.

Sheppard, L. D., \& Aquino, K. (2013). Much ado about nothing: Observers' problematization of women's same-sex conflict at work. Academy of Management Perspectives, 27, 52-62. doi: $10.5465 / \mathrm{amp} .2012 .0005$. 
Steele, C. M., \& Aronson, J. (1995). Stereotype threat and the intellectual test performance of African Americans. Journal of Personality and Social Psychology, 69, 797-811. doi:10.1037/00223514.69.5.797.

Swim, J. K., Aikin, K. J., Hall, W. S., \& Hunter, B. A. (1995). Sexism and racism - Oldfashioned and modern prejudices. Journal of Personality and Social Psychology, 68, 199-214. doi: 10.1037/0022-3514.68.2.199.

Tajfel, H., \& Turner, J. C. (1979). An integrative theory of intergroup conflict. In W. G. Austin \& S. Worchel (Eds.), The social psychology of intergroup relations. Monterey: Brooks/Cole.

Turner, J. C., Oakes, P. J., Haslam, S. A., \& McGarty, C. (1994). Self and collective: Cognition and social context. Personality and Social Psychology Bulletin, 20, 454-463. doi:10.1177/0146167294205002.

Van Laar, C., Derks, B., \& Ellemers, N. (2013). Motivation for education and work in young Muslim women: The importance of value for ingroup domains. Basic and Applied Social Psychology, 35, 64-74. doi:10.1080/01973533.2012.746609.

Van Laar, C., Bleeker, D., Ellemers, N., \& Meijer, E. (2014). Ingroup and outgroup support for upward mobility: Divergent responses to ingroup identification in low status groups. European Journal of Social Psychology, 44, 563-577. doi: 10.1002/ejsp.2046.

BELLE DERKS is Professor of Social and Organizational Psychology at Utrecht University (the Netherlands). She studies psychological (motivation, performance) and physiological (cardiovascular reactivity, EEG, ERP) effects of stigma and group-based devaluation among gender and ethnic minority groups in performance settings. The research reported here was conducted while she was at Leiden University (the Netherlands).

COLETTE VAN LAAR is Professor of Social and Cultural Psychology at Leuven University (Belgium). Her research focuses on the social psychology of low social status and stigma, and the consequences of stigma for cognition, emotion, motivation and performance. This research was conducted while she was at Leiden University (the Netherlands).

NAOMI ELLEMERS is professor of Social and Organizational Psychology at Leiden University (the Netherlands). Her research on group processes and intergroup relations addresses a range of topics including the effects of status differences between groups, diversity in teams and organizations, career development of women and minorities, and motivation and commitment in work teams.

GAUWRIE RAGHOE received her MA degree in Social and Organizational Psychology from Leiden University. The study reported in this article constituted her MA thesis. 